\title{
PENGARUH KOMPENSASI KARYAWAN DAN KEPUASAN KERJA TERHADAP KECENDERUNGAN KECURANGAN PERBANKAN
}

\section{THE EFFECT OF EMPLOYEE COMPENSATION AND WORK SATISFACTION ON TRENDS OF BANKING FRAUD}

\author{
Benedicta Mega Haryanti $D^{\mathbf{1}}$, Muhammad Nuryatno ${ }^{2}$ \\ ${ }^{12}$ Universitas Trisakti Indonesia \\ 1'benebenee@gmail.com,2nanotrisakti@gmail.com
}

\begin{abstract}
Abstrak
Tujuan dari penelitian ini adalah untuk mendapatkan bukti empiris mengenai pengaruh kompensasi karyawan terhadap kecenderungan kecurangan pada perusahaan perbankan dan pengaruh kepuasan kerja terhadap kecenderungan kecurangan pada perusahaan perbankan. Variabel yang digunakan dalam penelitian ini adalah kompensasi karyawan, kepuasan kerja, dan kecenderungan kecurangan perbankan, dimana data yang dikumpulkan merupakan data primer dan diperoleh dari penyebaran kuesioner. Penelitian ini menggunakan sampel berjumlah 100 orang individu yang merupakan individu-individu yang bekerja di perusahaan perbankan. Metode yang digunakan dalam penelitian ini adalah analisis regresi linear berganda. Hasil penelitian ini adalah (1) terdapat pengaruh negatif dan signifikan antara kompensasi karyawan terhadap kecenderungan kecurangan pada perusahaan perbankan (2) terdapat pengaruh negatif dan signifikan antara kepuasan kerja terhadap kecenderungan kecurangan pada perusahaan perbankan. Variabel independen dapat menjelaskan sebaan variabel dependen sebesar $49,2 \%$ sedangkan sisanya dijelaskan oleh faktor lain yang tidak terdapat dalam penelitian. Implikasi dari penelitian ini bagi perusahaan perbankan adalah perusahaan perbankan dapat meningkatkan kompensasi karyawan dan kepuasan kerja untuk mengurangi kecenderungan kecurangan pada perusahaan perbankan. Bagi peneliti selanjutnya agar dapat menambah jumlah sample dan jumlah variabel independen.
\end{abstract}

Kata Kunci : Kecurangan Perbankan, Kompensasi Karyawan, Kepuasan Kerja

\section{Abstract}

The purpose of this study is to obtain empirical evidence about the effect of employee compensation on the tendency of fraud in banking companies and the influence of job satisfaction on the tendency of fraud on banking companies. Variables used in this study are employee compensation, job satisfaction, and the tendency of banking fraud, where the data collected is primary data and obtained from questionnaires. This study uses a sample of 100 individuals who work in banking companies. The method used in this study is the multiple linear regression analysis. The results of this study are (1) there is negative and significant influence between employee compensation for the tendency of fraud on banking companies (2) there is negative and significant influence between job satisfaction on the tendency of fraud in banking companies. Independent variables can explain the dependent variable of $49.2 \%$ while the rest is explained by other factors not found in the study. The implication of this study for banking companies is that banking companies can increase employee compensation and job satisfaction in order to reduce the tendency of fraud on banking companies. For further researchers, it is expected to increase the number of samples and the number of independent variables.

Keywords: Banking Fraud, Employee Compensation, Job Satisfaction 


\section{PENDAHULUAN}

Kecurangan perbankan merupakan tindak pidana dimana seseorang dengan sengaja mengeksekusi, atau mencoba mengeksekusi,sebuah skema atau kecurangan,untuk menipu lembaga keuangan, atau untuk mendapatkan properti yang dimiliki oleh atau di bawah kendali sebuah institusi keuangan, melalui kesalahan atau penipuan, permainan peran, atau janji-janji (Garner, 2004).

Berdasarkan hasil Fit and Proper Test Existing terhadap direksi, komisaris, dan pemegang saham pengendali pada laporan tahunan OJK tahun 2015, terdapat 13 pelaku dugaan penyimpangan yang terdiri dari tujuh direksi dan enam pejabat eksekutif. Modus dari fraud yang dilakukan antara lain penyalahgunaan wewenang, penyalahgunaan dana nasabah/debitur untuk kepentingan pribadi, pelanggaran ketentuan pemberian fasitlitas kredit, pelanggaran prinsip kehati-hatian dan asas pemberian kredit yang sehat, pelanggaran sistem dan prosedur pemberian fasilitas stand by financing, penyembunyian atau pengaburan pelanggaran dari suatu ketentuan, kondisi keuangan, atau transaksi yang sebenarnya, dan keterkaitan dengan kasus yang sedang dalam proses penyidikan.

Pada laporan tahunan OJK tahun 2015 juga ditemukan bahwa pada tahun 2015, penganganan dugaan tindak pidana perbankan adalah dibidang perkredian sebesar $62 \%$, penggelapan dana sebesar 19\%, rekayasa pencatatan sebesar 11\%, dan transfer dana sebesar $8 \%$. Adapun jumlah pelaku fraud yang diduga melakukan tindak pidana perbankan sebanyak 1 pemegang saham, dua komisaris, 25 direksi, 18 pejabat eksekutif, dan empat karyawan.

Melihat sejumlah kasus yang terjadi seperti yang dijabarkan pada uraian di atas, masyarakat umum sebagai nasabah bank tentu dapat mempertanyakan keamanan simpanannya yang ada pada bank. Hal ini dapat mempengaruhi kepercayaan masyarakat terhadap bank, sementara kepercayaan adalah dasar dari setiap transaksi yang terjadi dalam sebuah bank (Plasmeijer \& Raaij, 2017).

\section{TINJAUAN PUSTAKA DAN HIPOTESIS}

\section{Kompensasi Karyawan}

Kompensasi merupakan imbalan jasa atau balas jasa yang diberikan oleh perusahaan kepada tenaga kerja karena tenaga kerja tersebut telah memberikan sumbangan tenaga dan pikiran demi kemajuan perusahaan guna mencapai tujuan yang telah ditetapkan. (Sastrohadiwiryo, 2003)

Kompensasi merupakan imbalan jasa atau balas jasa yang diberikan oleh perusahaan kepada tenaga kerja karena tenaga kerja tersebut telah memberikan sumbangan tenaga dan pikiran demi kemajuan perusahaan guna mencapai tujuan yang telah ditetapkan. (Sastrohadiwiryo, 2003)

Gary Dessler (2009) mengemukakan bahwa kompensasi merupakan semua bentuk pembayaran atau hadiah yang diberikan kepada karyawan dan muncul dari pekerjaan mereka dan mempunyai 2 komponen, yaitu:

1. Pembayaran langsung

Contoh: upah, gaji, insentif, komisi, dan bonus.

2. Pembayaran tidak langsung

Contoh: asuransi, cuti, dan pinjaman karyawan

Menurut Bergmann and Scarpello (2001), sistem kompensasi telah sejak lama dirancang untuk menarik dan mempertahankan karyawan dan untuk memotivasi mereka untuk meningkatkan usahanya dalam mencapai tujuan perusahaan. Pemberian kompensasi oleh perusahaan juga dilatarbelakangi oleh beberapa tujuan sebagai berikut yang disampaikan oleh Davis dan Werther (1996) dalam Sigit (2010):

1. Memperoleh personil yang berkualifikasi.

2. Mempertahankan kayawan yang ada.

3. Menjamin keadilan. 
4. Penghargaan terhadap perilaku yang diinginkan.

5. Mengendalikan biaya.

6. Mengikuti aturan hukum.

Setiap perusahaan memiliki kebijakan yang berbeda-beda dalam haL bagaimana ia memberikan kompensasi kepada karyawannya. Sistem pemberian kompensasi yang seringkali diterapkan perusahaan menurut Hasibuan (2009) diantaranya adalah:

\section{Sistem waktu}

Perusahaan yang menerapkan sistem waktu dalam pemberian kompensasi kepada karyawannya menetapkan besarnya kompensasi (gaji, upah) berdasarkan standar waktu misalnya jam, minggu, atau bulan.

2. Sistem hasil (Output)

Apabila perusahaan menerapkan sistem hasil, besarnya kompensasi yang diberikan kepada karyawannya ditetapkan dengan menggunakan satuan unit yang dihasilkan oleh karyawan, misalnya per kilogram, per potong, atau per meter.

\section{Sistem borongan}

Kompensasi yang diberikan kepada karyawan oleh perusahaan yang menerapkan sistem borongan ditetapkan berdasarkan volume pekerjaan yang telah diselesaikan atau lama pengerjaannya.

\section{Kepuasan Kerja}

Kepuasan Kerja adalah kepuasan pegawai terhadap pekerjaannya, antara apa yang diharapkan dengan apa yang diterima dari pekerjaan/kantornya (Davis, 2004). Menurut Hulin dan Judge (2003), kepuasan kerja mencakup tanggapan psikologis multidimensional terhadap suatu pekerjaan, dimana tanggapan ini terdiri dari komponen kognitif, afektif, dan perilaku.

Sementara itu, Bernstein dan Nash (2008) mengartikan kepuasan kerja sebagai komponen emosional, kognitif, dan perilaku dari seorang karyawan. Komponen emosional mengacu pada perasaan seorang karyawan terhadap pekerjaannya, seperti rasa bosan, cemas, atau rasa senang. Komponen kognitif dari kepuasan kerja mengacu pada kepercayaan atau cara pandang seseorang terhadap suatu pekerjaan, apakah pekerjaan tersebut menantang. Komponen perilaku mencakup perilku seseorang atau aksi yang dilakukannya terkait dengan suatu pekerjaan, misalnya mogok kerja, datang telambat, atau berpura-pura sakit untuk menghindari pekerjaannya. Karyawan akan mencapai kepuasan kerja apabila yang diharapkan olehnya sama dengan apa yang diperolehnya.

\section{Kecenderungan Kecurangan Pada Perusahaan Perbankan}

Kecurangan adalah tindak pidana dimana seseorang dengan sengaja mengeksekusi, atau mencoba mengeksekusi, sebuah skema atau kecurangan, untuk menipu lembaga keuangan, atau untuk mendapatkan properti yang dimiliki oleh atau di bawah kendali sebuah institusi keuangan, melalui kesalahan atau penipuan, permainan peran, atau janji-janji (Garner, 2004).

Menurut Simanjuntak (2008), ada beberapa faktor yang menyebabkan seorang individu melakukan kecurangan yaitu:

\section{Faktor Generik/Umum}

Faktor generik/umum berhubungan dengan organisasi sebagai korban perilaku kecurangan. Faktor ini terdiri dari:

\section{a. Kesempatan (Oppurtunity)}


Kesempatan untuk melakukan kecurangan tergantung pada kedudukan pelaku terhadap objek kecurangan. Kesempatan untuk melakukan kecurangan selalu ada ada pada setiap jabatan yang ada di dalam perusahaan, akan tetapi secara umum, manajemen perusahaan mempunyai peluang yang lebih besar dibandingkan dengan karyawan biasa untuk melakukan tindak perilaku kecurangan.

b. Pengungkapan (Exposure)

Terungkapnya suatu kasus tindak perilaku kecurangan dalam perusahaan tidak dapat menjamin kasus tersebut tidak akan terulang kembali, baik oleh pelaku yang sama, maupun oleh orang lain. Karena itu, jika suatu tindak perilaku kecurangan terungkap, pelakunya harus dikenakan sanksi.

2. Faktor Individu

Faktor ini berhubungan dengan diri individu secara personal sebagai pelaku tindak kecurangan. Faktor ini mencakup:

a. Ketamakan (Greed)

Berhubungan dengan moral seseorang. Moral setiap individu terbentuk dari pandangan hidupnya masing-masing serta lingkungan tempat ia tumbuh dan berkembang.

b. Kebutuhan (Need)

Kebutuhan berhubungan dengan pandangan atau pemikiran seorang individu terhadap tingkat keperluannya terkait dengan aset yang dimiliki perusahaan tempatnya bekerja. Selain itu, tekanan (pressure) yang dihadapi oleh seorang individu dalam pekerjaannya dapat menyebabkan orang yang jujur mempunyai motif untuk melakukan tindak kecurangan.

Pelaku tindak kecurangan dalam suatu perusahaan terdiri dari:

1. Internal perusahaan

a. Karyawan

Karyawan atau pekerja yang melakukan tindak kecurangan melakukannya dengan tujuan untuk memperoleh keuntungan secara pribadi.

b. Manajemen

Biasanya kecurangan yang dilakukan oleh pihak manajemen dilakukan untuk kepentngan perusahaan, misalnya dalam hal pelaporan laporan keuangan yang dimanipulasi sedemikian rupa agar lapoan keungan terlihat bagus dan menarik bagi investor.

2. Eksternal perusahaan

Pihak eksternal yang berhubungan dengan perusahaan juga memiliki potensi untuk melakukan kecurangan. Contohnya antara lain adalah auditor dan akuntan publik. Konflik kepentingan akan muncul apabila mereka tidak melaksanakan kode etik profesinya dengan baik. Selain auditor dan akuntan publik, pihak lain yang memiliki potensi untuk melakukan kecurangan juga dapat berasal dari pelanggan, supplier, maupun distributor perusahaan.

Kecurangan perbankan ini dapat terjadi selama perusahaan perbankan menjalankan usahanya (Hardanto, 2006).

Atas dasar uraian teori dan penelitian sebelumnya, maka dalam penelitian ini akan diajukan hipotesa sebagai berikut:

H1 : Terdapat pengaruh signifikan negatif kompensasi karyawan terhadap kecurangan pada perusahaan perbankan.

H2 : Terdapat pengaruh signifikan negatif kepuasan kerja terhadap kecurangan pada perusahaan perbankan. 
Tabel 1. Pengukuran Variabel Dependen dan Independen

\begin{tabular}{|c|c|c|c|}
\hline Variabel & Indikator & $\begin{array}{c}\text { Skala } \\
\text { Pengukuran } \\
\end{array}$ & $\begin{array}{c}\text { Butir } \\
\text { Kuesioner }\end{array}$ \\
\hline Kompensasi & Upah dan gaji & Skala Likert & 2 \\
\hline \multirow[t]{3}{*}{ Karyawan } & Insentif & & 1 \\
\hline & Tunjangan & & 3 \\
\hline & Fasilitas & & 2 \\
\hline Kepuasan & Kesempatan untuk maju & Skala Likert & 2 \\
\hline \multirow[t]{10}{*}{ Kerja } & Keamanan & & 2 \\
\hline & Gaji dan Upah & & 2 \\
\hline & $\begin{array}{l}\text { Situasi dan kondisi kerja yang } \\
\text { stabil }\end{array}$ & & 1 \\
\hline & $\begin{array}{l}\text { Adanya pengawas atau } \\
\text { supervisor }\end{array}$ & & 1 \\
\hline & Faktor instrinsik pekerjaan & & 1 \\
\hline & Kondisi kerja & & 1 \\
\hline & Aspek sosial dalam pekerjaan & & 1 \\
\hline & Komunikasi antar karyawan & & 2 \\
\hline & Fasilitas lainnya yang diberikan & & 2 \\
\hline & perusahaan & & 2 \\
\hline Kecurangan & Manipulasi & Skala Likert & 1 \\
\hline \multirow[t]{4}{*}{ Perbankan } & Pemalsuan dokumen & & 1 \\
\hline & Penghilangan Informasi & & 1 \\
\hline & Penggelapan aktiva & & 1 \\
\hline & $\begin{array}{l}\text { Pelanggaran terhadap prinsip } \\
\text { akuntansi }\end{array}$ & & 1 \\
\hline
\end{tabular}

Sumber: Berbagai Literatur Pendukung

Tabel 2. Statistik Deskiptif

\begin{tabular}{cccccc}
\hline Variabel & N & Minimum & Maximum & Mean & $\begin{array}{c}\text { Std, } \\
\text { Deviation }\end{array}$ \\
\hline Kompensasi Karyawan & 100 & 1,75 & 5,00 & 4,2087 & 0,72715 \\
Kecenderungan & 100 & 1,00 & 4,20 & 1,4120 & 0,69621 \\
Kecurangan & 100 & 1,63 & 5,00 & 3,9894 & 0,72464 \\
Kepuasan Kerja &
\end{tabular}

Sumber: Hasil Pengolahan Data dengan Software SPSS 23

Dengan melihat tabel di atas, dapat dijelaskan demikian, pada variabel Kompensasi Karyawan diketahui berdasarkan jumlah sampel sebesar 100 didapat jawaban terendah responden berkisar di nilai 1,75 (cenderung tidak setuju) dengan nilai jawaban tertinggi berkisar di nilai 5,00 (sangat setuju), adapun nilai rata-rata persepsi responden pada variabel Kompensasi Karyawan adalah sebesar 4,2087 dengan standar deviasi sebesar 0,72715, sehingga disimpulkan bahwa responden menyatakan setuju pada tiap-tiap item pernyataan Kompensasi Karyawan.

Pada variabel Kecenderungan Kecurangan diketahui berdasarkan jumlah sampel sebesar 100 didapat jawaban terendah responden berkisar di nilai 1,00 (sangat tidak setuju) dengan nilai jawaban tertinggi berkisar di nilai 4,20 (setuju), adapun nilai rata-rata persepsi responden pada variabel Kecenderungan Kecurangan adalah sebesar 1,4120 dengan standar deviasi sebesar 0,69621, sehingga disimpulkan bahwa responden menyatakan sangat tidak setuju pada tiap-tiap item pernyataan Kecenderungan Kecurangan. 
Pada variabel Kepuasan Kerja diketahui berdasarkan jumlah sampel sebesar 100 didapat jawaban terendah responden berkisar di nilai 1,63 (tidak setuju) dengan nilai jawaban tertinggi berkisar di nilai 5,00 (sangat setuju), adapun nilai rata-rata persepsi responden pada variabel Kepuasan Kerja adalah sebesar 3,9894 dengan standar deviasi sebesar 0,72464, sehingga disimpulkan bahwa responden menyatakan setuju pada tiap-tiap item pernyataan Kepuasan Kerja.

\section{METODE}

\section{Uji Asumsi Klasik}

\section{Uji Normalitas}

Uji normalitas bertujuan untuk menguji apakah dalam model regresi, variabel terikat dan variabel bebas keduanya mempunyai distribusi normal ataukah tidak. Uji Normalitas dilakukan dengan analisis Grafik Normal P-P Plot dan Kolmogorov-Smirnov Test. Hasil uji normalitas ditunjukkan pada gambar dan tabel di bawah ini:

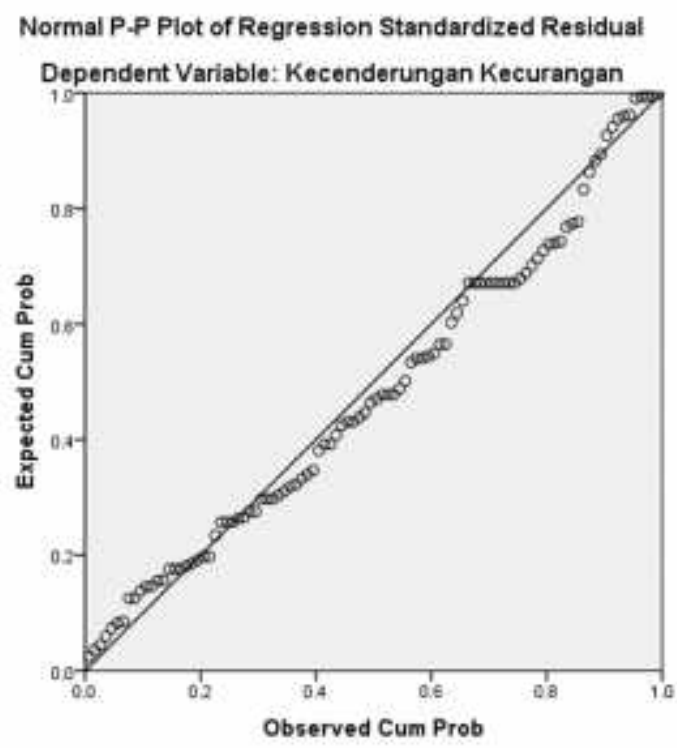

Gambar 1. Hasil Uji Normalitas Regresi Berganda Sumber: Hasil Pengolahan Data dengan Software SPSS 23

Dari hasil uji normalitas Gambar 1 di atas diketahui bahwa data di sekitar garis diagonal dan mengikuti arah garis diagonalnya, maka model regresi telah memenuhi asumsi normalitas.

Tabel 3. Hasil Uji Normalitas Kolmogorov-Smirnov Test

\begin{tabular}{ccc}
\hline Variabel & Sig. & Keputusan \\
\hline Unstandardized residual & 0,071 & Normal \\
\hline Sumber: Hasil Pengolahan Data dengan Software SPSS 23
\end{tabular}

Berdasarkan Tabel 3 di atas, dapat diketahui bahwa uji kolmogorov-smirnov test memiliki nilai signifikansi lebih besar dari 0,05 yaitu sebesar 0,071 , maka $\mathrm{H}_{0}$ gagal ditolak yang berarti model regresi yang digunakan mempunyai standar error yang normal, sehingga dapat disimpulkan bahwa model regresi dapat diuji lebih lanjut untuk mengetahui pengaruh masing-masing variabel bebas terhadap variabel terikat. 


\section{Uji Multikolinearitas}

Multikolinearitas menunjukkan bahwa antara variabel bebas mempunyai hubungan langsung (korelasi) yang sangat kuat. Multikolinearitas terjadi jika nilai Variance Inflation Factor (VIF) lebih besar dari 10 atau nilai Tolerance lebih kecil 0,10. Uji Multikolinearitas dapat dilihat pada tabel di bawah ini:

Tabel 4. Hasil Pengujian Multikolinearitas

\begin{tabular}{llcl}
\hline \multicolumn{1}{c}{ Variabel Bebas } & Tolerance & VIF & Keputusan \\
\hline Kompensasi Karyawan & 0.310 & 3.223 & Tidak ada multikolinearitas \\
Kepuasan Kerja & 0.310 & 3.223 & Tidak ada multikolinearitas \\
\hline
\end{tabular}

Sumber: Hasil Pengolahan Data dengan Software SPSS 23

Dari Tabel 4 uji multikolinearitas di atas, diketahui bahwa seluruh variabel independen mempunyai nilai VIF yang kurang dari 10 dan nilai tolerance lebih besar dari 0,10, sehingga $\mathrm{H}_{0}$ diterima, yang berarti seluruh variabel independen yang digunakan pada model persamaan regresi tidak ada multikolinearitas (tidak ada hubungan yang sangat kuat antara variabel independen).

\section{Uji Heteroskedastisitas}

Heteroskedastisitas menunjukkan bahwa varians dari setiap eror bersifat heterogen yang berarti melanggar asumsi klasik yang mensyaratkan bahwa varians dari error harus bersifat homogen. Pengujian dilakukan dengan uji Park.

Hipotesa Heteroskedastisitas :

Ho : tidak ada Heteroskedastisitas

$\mathrm{Ha}$ : ada Heteroskedastisitas

Dasar Pengambilan Keputusan :

Jika probabilitas (Sig.) $>0,05, \mathrm{H}_{0}$ diterima varians error homogen (tidak ada heteroskedastisitas).

Jika probabilitas (Sig.) $<0,05, \mathrm{H}_{0}$ ditolak varians error heterogen (ada heteroskedastisitas). Hasil pengujian heteroskedastisitas ditunjukkan pada tabel berikut :

Tabel 5. Pengujian Heteroskedastisitas

\begin{tabular}{lrr}
\hline \multicolumn{1}{c}{ Variabel Bebas } & Sig. & Keputusan \\
\hline Kompensasi Karyawan & 0,366 & Tidak ada heteroskedastisitas \\
Kepuasan Kerja & 0,099 & Tidak ada heteroskedastisitas \\
\hline
\end{tabular}

Sumber: Hasil Pengolahan Data dengan Software SPSS 23

Berdasarkan Tabel di atas, diketahui nilai probabilitas dari seluruh variabel independen lebih besar dari 0,05 , maka $\mathrm{H}_{0}$ diterima, sehingga dapat disimpulkan tidak ada heteroskedastisitas pada model regresi yang digunakan.

\section{Pengujian Hipotesis}

\section{Koefisien Determinasi}

Koefisien determinasi $\left(\mathrm{R}^{2}\right)$ pada intinya mengukur seberapa jauh kemampuan model dalam menerangkan variasi variabel dependen. Nilai koefisien determinasi adalah antara nol dan satu. Nilai $\mathrm{R}^{2}$ yang kecil berarti kemampuan variabel-variabel independen secara keseluruhan dalam menjelaskan variabel-variabel dependen sangat terbatas. Nilai yang mendekati satu berarti seluruh variabel-variabel independen memberikan hampir semua informasi yang dibutuhkan untuk memprediksi variasi variabel dependen. 
Tabel 6. Hasil Uji $\mathrm{R}^{2}$ dan Adjusted $\mathrm{R}^{2}$

\begin{tabular}{cc}
\hline $\mathbf{R}^{2}$ & Adjusted $\mathbf{R}^{2}$ \\
\hline 0,503 & 0,492 \\
\hline
\end{tabular}

Sumber: Hasil Pengolahan Data dengan Software SPSS 23

Berdasarkan Tabel 6 hasil pengujian regresi didapat nilai adjusted $R^{2}$ adalah 0,492. Artinya seluruh variabel independen yang terdiri dari Kompensasi Karyawan dan Kepuasan Kerja mampu menjelaskan variasi dari variabel dependen yaitu Kencenderungan Kecurangan sebesar $49,2 \%$, sedangkan sisanya dapat dijelaskan oleh faktor-faktor lain yang tidak diikutsertakan dalam model.

\section{Uji Statistik F (ANOVA)}

Uji statistik F atau ANOVA pada dasarnya untuk menguji apakah semua variabel independen atau bebas yang dimasukkan dalam model dapat berpengaruh secara bersamasama atau tidak terhadap variabel dependen.

Tabel 7. Hasil Uji F (Uji Serentak)

\begin{tabular}{cc}
\hline F-hitung & Sig. \\
\hline 49,031 & 0,000 \\
\hline
\end{tabular}

Sumber: Hasil Pengolahan Data dengan Software SPSS 23

$\mathrm{H}_{0}$ : secara bersama-sama tidak terdapat pengaruh antara Kompensasi Karyawan dan Kepuasan Kerja terhadap Kecenderungan Kecurangan.

$\mathrm{H}_{\mathrm{a}}$ : secara bersama-sama terdapat pengaruh antara Kompensasi Karyawan dan Kepuasan Kerja terhadap Kecenderungan Kecurangan.

Berdasarkan hasil uji $\mathrm{F}$ Tabel 7 di atas diketahui bahwa F-hitung sebesar 49,031 dengan nilai signifikansi sebesar $0,000<\alpha_{0,05}$, maka $\mathrm{H}_{0}$ ditolak yang berarti secara bersamasama terdapat pengaruh antara Kompensasi Karyawan dan Kepuasan Kerja terhadap Kecenderungan Kecurangan.

\section{Uji t (Pengujian Hipotesis)}

Analisis data diperoleh dari hasil pengujian terhadap hipotesis. Pengujian hipotesa digunakan untuk melihat apakah terdapat pengaruh secara individu variabel bebas terhadap variabel terikat. Untuk menguji hipotesa dilakukan dengan uji statistik t yaitu apakah satu variabel independen secara individual dapat berpengaruh atau tidak terhadap variabel dependen dengan mengasumsikan variabel lain adalah konstan.

Dasar pengambilan keputusan

Jika $\rho$-value < alpha 0,05 maka $\mathrm{H}_{0}$ ditolak

Jika $\rho$-value > alpha 0,05 maka $\mathrm{H}_{0}$ gagal ditolak.

Tabel 8. Hasil Uji t Regresi Berganda

\begin{tabular}{cccccc}
\hline Variabel Bebas & $\begin{array}{c}\text { Expected } \\
\text { Sign }\end{array}$ & Koefisien & Sig. & $\begin{array}{c}\text { Sig. } \\
\text { 1-Tailed }\end{array}$ & Keputusan \\
\hline (Constant) & & 4,332 & 0,000 & 0,000 & \\
Kompensasi Karyawan & negatif & $-0,394$ & 0,002 & 0,001 & H1 diterima \\
Kepuasan Kerja & negatif & $-0,316$ & 0,012 & 0,006 & H2 diterima \\
\hline
\end{tabular}

Sumber: Hasil Pengolahan Data dengan Software SPSS 23 


\section{HASIL DAN PEMBAHASAN}

\section{$\mathrm{H}_{1} \quad$ : Pengaruh Kompensasi Karyawan terhadap Kecenderungan Kecurangan}

Variabel kompensasi karyawan mempunyai koefisien regresi $(\beta 1)=-0,394$ dengan sig. 0,001 . Nilai sig. lebih kecil dari nilai probabilitas 0,05 atau $0,001<0,05$, maka $\mathrm{H}_{0}$ ditolak dan $\mathrm{H}_{1}$ diterima. Hal ini berarti hipotesis yang menyatakan bahwa terdapat pengaruh signifikan negatif kompensasi karyawan terhadap kecenderungan kecurangan pada perusahan perbankan dapat diterima dengan kata lain penelitian ini menyimpulkan terdapat pengaruh signifikan negatif kompensasi karyawan terhadap kecenderungan kecurangan pada perusahan perbankan. Variabel kompensasi karyawan mempunyai koefisien regresi $(\beta 1)=-$ 0,394 dan memiliki nilai negatif, maka dapat disimpulkan bahwa kompensasi karyawan memiliki hubungan negatif dan signifikan dengan kecenderungan kecurangan. Nilai $\beta$ negatif menunjukkan bahwa variabel X1 mempunyai hubungan yang berbalik arah dengan Y. Dengan kata lain semakin tinggi kompensasi karyawan akan membuat kecenderungan kecurangan semakin menurun, dan pengaruh tersebut signifikan secara statistik. Hal ini tidak sejalan dengan penelitian Bartenputra (2016) mengenai Pengaruh Kesesuaian Kompensasi, Ketaatan Akuntansi, dan Asimetri Informasi Terhadap Kecenderungan Kecurangan Akuntansi dimana hasilnya menunjukkan bahwa kesesuaian kompensasi tidak berpengaruh terhadap kecenderungan kecurangan akuntansi. Namun hasil penelitian ini sejalan dengan penelitian yang dilakukan oleh Prasetya (2014) mengenai Pengaruh Kompensasi Terhadap Fraud dengan Kepuasan Kerja Sebagai Variabel Intervening dimana hasilnya menunjukkan bahwa kompensasi berpengaruh negatif terhadap fraud (kecurangan).

\section{$\mathbf{H}_{2} \quad$ : Pengaruh Kepuasan Kerja terhadap Kecenderungan Kecurangan}

Variabel kepuasan kerja mempunyai koefisien regresi $(\beta 2)=-0,316$ dengan sig. 0,006. Nilai sig. lebih kecil dari nilai probabilitas 0,05 atau 0,006 $<0,05$, maka $\mathrm{H}_{0}$ ditolak dan $\mathrm{H}_{2}$ diterima. Hal ini berarti hipotesis yang menyatakan bahwa terdapat pengaruh signifikan negatif kepuasan kerja terhadap kecenderungan kecurangan pada perusahan perbankan dapat diterima dengan kata lain penelitian ini menyimpulkan terdapat pengaruh signifikan negatif kepuasan kerja terhadap kecenderungan kecurangan pada perusahan perbankan. Variabel kepuasan kerja mempunyai koefisien regresi $(\beta 2)=-0,316$ dan memiliki nilai negatif, maka dapat disimpulkan bahwa kepuasan kerja memiliki hubungan negatif dan signifikan dengan kecenderungan kecurangan. Nilai $\beta$ negatif menunjukkan bahwa variabel X2 mempunyai hubungan yang berbalik arah dengan Y. Dengan kata lain semakin tinggi kepuasan kerja akan membuat kecenderungan kecurangan semakin menurun, dan pengaruh tersebut signifikan secara statistik. Hal ini sejalan dengan penelitian Rahmaidha (2017) mengenai Pengaruh Keefektifan Pengendalian Internal, Ketaatan Aturan Akuntansi, dan Kepuasan Kerja Terhadap Kecurangan Akuntansi dimana hasilnya menunjukkan bahwa terdapat pengaruh negatif dan signifikan antara kepuasan kerja terhadap kecenderungan kecurangan pada perusahaan perbankan.

\section{KESIMPULAN}

Berdasarkan penelitian yang dilakukan, diperoleh kesimpulan yaitu: (1) Kompensasi karyawan memiliki pengaruh signifikan negatif terhadap kecenderungan kecurangan pada perusahaan perbankan (2) Kepuasan kerja memiliki pengaruh signifikan negatif terhadap kecenderungan kecurangan pada perusahan perbankan.Terdapat kesamaan dan perbedaan dari hasil penelitian ini dengan hasil penelitian terdahulu. Perbedaan hasil terjadi karena adanya perbedaan subjek penelitian. 


\section{DAFTAR PUSTAKA}

As'ad, M. 2001. Psikologi Industri. Yogyakarta: Liberty.

Bartenputra, (2016) "Pengaruh Kesesuaian Kompensasi, Ketaatan Akuntansi dan Asimetri Informasi Terhadap Kecenderungan Kecurangan Akuntansi”. Jurnal Akuntansi. Vol 4 No: 2.

Bergmann, Thomas J. dan Scarpello, Vida Gulbinas. 2001. Compensation Decision Making. California: Harcout College Publisher.

Bernstein, D. A., \& Nash, P. W. 2008. Essentials of Psychology 4th edition. New. York: Houbhton Mifflin Company

Damiano Fiorillo, Nunzia Nappo, (2014) "Job satisfaction in Italy: individual characteristics and social relations". International Journal of Social Economics. Vol. 41 Issue: 8, Halaman 683-704.

Davis, Gordon B. 2004. Sistem Informasi Manajemen. Jakarta: Gramedia.

Dessler, Gary. 2009. Manajemen Sumber Daya Manusia. Jakarta: Indeks.

Garner, B.A. 2004. Black's Law Dictionary, 8th ed..ThomsonWest Group. St Paul,MN.

Hasibuan, Malayu S.P. 2009. Manajemen: Dasar, Pengertian, dan Masalah Edisi Revisi. Jakarta : Bumi Aksara

Hardanto, Sulad Sri. 2006. Manajemen Risiko Bagi Bank Umum.Jakarta: Elex Media Komputindo PT.

Hoffmann, Arvid O.I. , Cornelia Birnbrich. 2012. "The impact of fraud prevention on bankcustomer relationships: An empirical investigation in retail banking". International Journal of Bank Marketing. Vol. 30 Issue: 5, Halaman 390-407.

Hongming Cheng, Ling Ma, (2009) "White collar crime and the criminal justice system: Government response to bank fraud and corruption in China", Journal of Financial Crime, Vol. 16 Issue: 2

Hulin, C. L dan Judge, T. A. 1993." Job Satisfaction as a Reflection of Disposition: A Multiple-source Causal Analysis". Organizational Behavior and Human Decision Process Journal. 56, 388-421.

Notoatmodjo, Soekidjo. 1998. Pengembangan Sumber Daya Manusia. Jakarta: Rineka Cipta.

Pauline W.J. van Esterik-Plasmeijer, dan W. Fred van Raaij. 2017. "Banking system trust, bank trust, and bank loyalty". International Journal of Bank Marketing. Vol. 35 Issue: 1, Halaman 97-111.

Prasetya. (2014), "Pengaruh Kompensasi Terhadap Fraud dengan Kepuasan Kerja sebagai Variable Intervening”. Universitas Negeri Yogyakarta.

Werther, J. and Davis, K. 1996. Human Resources and Personnel Management 5th Edition. New York: McGraw-Hill.

Rivai, V. 2011. Manajemen Sumber Daya Manusia untuk Perusahaan dari Teori ke Praktik. Jakarta: PT. Rajagrafindo Persada. 
Sastrohadiwiryo, B. Siswanto. 2003. Manajemen Tenaga Kerja Indonesia, edisi 2. Jakarta: PT. Bumi Aksara.

Veithzal, Rivai. 2005. Manajemen Sumber Daya Manusia untuk Perusahaan. Jakarta : PT. Raja Grafindo Persada. 